\title{
INSERÇÕES DO ASSISTENTE SOCIAL EM SAÚDE MENTAL: EM FOCO O TRABALHO COM AS FAMÍLIAS
}

Lucia Cristina dos Santos Rosa ${ }^{I}$

Tânia Maria Ferreira Silva Melo ${ }^{2}$

\section{RESUMO}

O objetivo do presente texto é iniciar uma análise das diferentes inserções dos assistentes sociais na área da saúde mental, a partir da implementação do Movimento da Reforma Psiquiátrica Brasileira, tendo por destaque a atuação com os grupos familiares. Tem por base o resgate da literatura profissional e a experiência docente a partir da realidade nordestina. No contexto reformista as ações dos assistentes sociais encontramse em processo de construção, exigindo maiores sistematizações e aprofundamentos.

PALAVRAS-CHAVE: Serviço Social; Saúde Mental; Práticas Profissionais.

\section{MOVIMENTO DA REFORMA PSIQUIÁTRICA BRASILEIRA, O QUE HÁ DE NOVO NA SAÚDE MENTAL?}

A inserção do assistente social em saúde mental no Brasil, a partir dos anos 90 tem por determinante o processo de desinstitucionalização da pessoa com transtorno mental, isto é, todo um processo de "crítica epistemológica ao saber médico constituinte da psiquiatria" (AMARANTE, 1996, p. 22) e a todo aparato que deu suporte à institucionalização do modelo hospitalocêntrico de atenção a este segmento social, ou seja, todo arcabouço legal, técnico, administrativo e interventivo da psiquiatria clássica.

Supracitado processo deu origem à reforma psiquiátrica brasileira conceituada como "conjunto de transformações de práticas, saberes, valores culturais e sociais em

\footnotetext{
${ }^{1}$ Doutora em Serviço Social pela UFRJ. Docente do Curso de Serviço Social da Universidade Federal do Piauí

${ }^{2}$ Mestre em Políticas Públicas pela UFPI. Docente do Curso de Serviço Social do Instituto Camilo Filho. Assistente Social do Caps II Leste da Fundação Municipal de Saúde - Teresina-PI
} 
torno do "louco" e da "loucura", mas especialmente em torno das políticas públicas para lidar com a questão" (BRASIL, 2007, p. 58), que tem origem na década de 70, do século XX, no cerne do processo de redemocratização da sociedade brasileira. Primeiramente persiste subsumido ao Movimento Sanitário, mas, ganha uma identidade própria, haja visto que o primeiro tem como bandeira de luta a universalidade do direito à saúde, tendo por foco os direitos sociais. Por sua vez, o Movimento da Reforma Psiquiátrica orienta-se pelos direitos civis das pessoas com transtornos mentais, isto é, se insere na luta das minorias sociais pelas liberdades básicas, tais como: circular pela cidade e convívio social.

O modelo asilar/ hospitalocêntrico em psiquiatria emerge como uma resposta a uma das questões sociais postas pela pessoa com transtorno mental, com a emergência da sociedade moderna, fundamentada no trabalho, no ser da razão e da produção. Tais pessoas figuram no novo contexto como improdutivas (BASTIDE, 1967) e, portanto, são alijadas do convívio social, a partir da apropriação médica da loucura, definida desde então, como "doença mental", presumindo-se a periculosidade e incapacidade de tais sujeitos, fato que justificará no imaginário social a idéia de que "lugar de doido é no hospício". Supracitado modelo, sobretudo após a II Guerra Mundial, passa a ser equiparado a um campo de concentração, por ter se constituído em um espaço de violação de direitos humanos, pela ação centrada na massificação da atenção e na mera segregação social. Neste contexto emergem várias propostas reformistas em saúde mental, com diferentes tradições teóricas, em conjunturas históricas singulares e em vários países do mundo Ocidental, destacando-se a Inglaterra, a França, os Estados Unidos e a Itália. 
Desses processos, emerge paulatinamente, com mais intensidade a partir da década de 90, sobretudo no Brasil, a luta pela inclusão da pessoa com transtorno mental na condição cidadã, como sujeitos de direitos.

Coroando estes processos, a Organização Panamericana da Saúde realiza a Conferência Regional para a Reestruturação da Assistência Psiquiátrica, no período de 11 a 14 de novembro de 1990, em Caracas, Venezuela. Do encontro resulta a Declaração de Caracas, em que o "manicômio" é condenado tendo por base 04 eixos: 1 - Ético-jurídico - pela violação dos direitos humanos das pessoas com transtornos mentais;

2 - Clínico - em função da ineficácia terapêutica e da condição de agente patogênico e cronificador historicamente assumido por tais instituições;

3 - Institucional - devido tais instituições se constituírem como espaço de violência “instituições totais", que mortificam, sujeitam;

4 - Sanitário - em função da organização do modelo assistencial figurar como "cidade dos loucos", produzindo a loucura administrativa, executiva e organizacional (ORGANIZAÇÃO PANAMERICANA DA SAÚDE, 1990, p. 8).

Em reforço à tendência de reconhecimento da condição de sujeito de direitos da pessoa com transtorno mental, em 17 de dezembro de 1991 a Organização das Nações Unidas divulga o documento que trata da "proteção de pessoas com problemas mentais e a melhoria da assistência à saúde mental”.

Em suma, o que singulariza as reformas psiquiátricas em curso no mundo Ocidental no pós II Guerra e a partir dos anos 70 no Brasil é a construção da cidadania da pessoa com transtorno mental, até então tuteladas. Paradoxalmente, o desafio que é colocado é de revisão da "cidadania interditada" (DELGADO, 1992). 
O movimento brasileiro é influenciado pela experiência italiana, da tradição basagliana (AMARANTE, 1996), que coloca a enfermidade entre parênteses, evidenciando o sujeito enfermo e seu contexto de vida. Constrói seu objeto sobre a complexidade da "existência-sofrimento" (ROTELLI, 1990) das pessoas com transtornos mentais, articulando-a com suas condições de reprodução social, enfatizando o processo de invenção/produção da saúde.

Nesta leitura a questão a ser enfrentada é a emancipação, a ampliação do poder de trocas sociais das pessoas com transtornos mentais, não a obstinação terapêutica pela cura ou a reparação, mas a reprodução social, a reinscrição dessas pessoas no mundo social.

Tal perspectiva se sintoniza com o conceito ampliado de saúde advogado pelo Sistema Único de Saúde, reforçado pela Constituição Federal de 1988, em que os determinantes sociais do processo saúde-doença ganham destaque. A saúde é vinculada às condições de reprodução da vida. Passa a abranger: o meio físico; o meio sócioeconômico e cultural e a oportunidade de acesso aos serviços que visem à promoção, proteção e recuperação da saúde. Emerge assim um novo paradigma, baseado na promoção da saúde, onde a qualidade de vida e a atenção integral são ressaltadas.

Tais entendimentos, associados aos avanços da bioética e princípios do controle social das ações do Estado pelos Movimentos Sociais impõem uma ampliação do campo clínico, que ganha uma denominação específica na área psi, como clínica da reforma; clínica do cotidiano ou clínica ampliada. Ou seja, a dimensão socioeconômica, política e cultural são integradas na abordagem dos profissionais que advogam esta perspectiva. O clínico e o extra-clínico não mais se dissociam.

Anteriormente, tratar circunscrevia limitar-se às expressões dos sintomas da enfermidade, à terapia medicamentosa ou a intervenção exclusiva ou 
preponderantemente médica. O que era da enfermidade era considerado clínico, então remetido ao médico. O extra-clínico, o social, era remetido a outros profissionais, principalmente ao assistente social.

“A Clínica Ampliada propõe que o profissional de saúde desenvolva a capacidade de ajudar as pessoas, não só a combater as doenças, mas a transformar-se, de forma que a doença, mesmo sendo um limite, não a impeça de viver outras coisas na sua vida" (BRASIL, 2004).

Com estes arcabouços, desenvolvem-se no Brasil várias experiências inovadoras em saúde mental, combatendo o estigma que historicamente cercou este segmento bem como consolidam-se alterações no plano assistencial e legislativo.

Em 1989 é apresentado o Projeto de Lei $\mathrm{n}^{\circ} 3.657 / 89$ de autoria do deputado mineiro Paulo Delgado, que propõe a extinção dos manicômios e sua substituição por serviços extra-hospitalares. Este projeto impulsionou os debates em torno da construção da cidadania das pessoas com transtornos mentais na década de 90 no país, levando 12 anos para se transformar em uma lei específica.

No início dos anos 90 a Coordenação de Saúde Mental do Ministério da Saúde adota uma política de reestruturação da assistência psiquiátrica, orientada para a criação de novos serviços, posto que, até então, o governo federal só financiava serviços identificados com o modelo hospitalocêntrico.

No plano legislativo as inovações circunscrevem os avanços estabelecidos pela Lei $\mathrm{n}^{\mathrm{o}}$ 10.216, de 6 de abril de 2001, que "dispõe sobre a proteção e os direitos das pessoas portadoras de transtornos mentais e redireciona o modelo assistencial em saúde mental". 
Em 2002 o Ministério da Saúde lança a Portaria $\mathrm{n}^{\mathbf{0}}$ 336, que define as modalidades de Centros de Atenção Psicossocial - CAPs, principal equipamento reformista, colocado como substitutivo ao modelo hospitalocêntrico.

Os Caps são definidos pela portaria acima como serviço ambulatorial, que funciona segundo a lógica do território, devendo priorizar o atendimento de pessoas com transtornos mentais severos e persistentes.

O território ${ }^{3}$ é entendido como a esfera da gestão da vida cotidiana da pessoa com transtorno mental. Circunscreve os espaços construídos e reconstruídos permanentemente, resultando do jogo de interesses entre diversos atores sociais. Desse modo, cabe à intervenção do Caps propiciar laços sociais e melhorar a vida cotidiana da pessoa com transtorno mental. O cuidado oferecido vai além da debelação dos sintomas, abarcando o lazer, as relações sociais, as condições de moradia, as atividades da vida diária, a esfera da geração de renda/trabalho, dentre outras.

O paradigma que orienta a nova perspectiva e prática circunscreve o amplo campo denominado de reabilitação psicossocial, um termo polissêmico mas, no contexto do presente texto compreendido como

um processo que implica a abertura de espaços de negociação para o paciente, para sua família, para a comunidade circundante e para os serviços que se ocupam do paciente: a dinâmica da negociação é continua e não pode ser codificada de uma vez por todas, já que os atores (e os poderes) em jogo são muitos e reciprocamente multiplicantes (SARACENO, 1999, p. 112).

Saraceno equipara o conceito de reabilitação psicossocial à cidadania, entendendo-os como sinônimos.

\footnotetext{
${ }^{3}$ Definição estabelecida por Erotildes Leal, em aula sobre a Clínica da Reforma em 2005. Revista Serviço Social \& Saúde. UNICAMP Campinas, v. VII-VIII, n. 7-8, Dez. 2009
} 
Nesta perspectiva vários elementos assumem papel de destaque na evolução de um transtorno mental, assim como na estratégia da intervenção em saúde mental. Saraceno (1994) classifica estes elementos dividindo-os em variáveis fortes e variáveis sombra. As primeiras são delimitadas pelo: diagnóstico; idade; agudeza ou cronicidade do quadro e historia da enfermidade (p. 21). As variáveis denominadas como "sombra" não são menos importantes, mas, contornam uma gama de fatores que se relacionam com: a) os recursos individuais da pessoa com transtorno mental ("o nível de capacidade intelectual e o grau de informação" da pessoa com transtorno mental, seu status social, sua condição de solidão ou não e o sexo. (p. 21). Entre os recursos do contexto, são destacados: o nível de comprometimento relacional dos familiares; nível de solidariedade ou hostilidade da rede de parentesco ou de vizinhança; o status social do grupo familiar e nível de integração ou desintegração social do meio em que vive. Entre os recursos do serviço assistencial, Saraceno (1999) destaca os recursos materiais, organizacional e os processos de trabalho.

Dentre os recursos do contexto do serviço de atenção, os elementos que podem favorecer ou obstaculizar o sucesso da intervenção estão relacionados ao: nível de solidariedade da rede social; nível de articulação da rede sócio-assistencial; qualidade e eficiência do sistema de saúde do país e atitude, positiva ou negativa dos demais serviços sócio-assistenciais em relação às decisões da equipe da saúde mental. Todavia, conforme alerta Saraceno:

Essas variáveis geralmente são deixadas à sombra porque são consideradas "irrelevantes" no que diz respeito à evolução da enfermidade e à estratégia de intervenção. Entretanto, é provável que um paciente piore muito mais pela falta de todos (ou alguns) desses recursos do que pelo tipo de enfermidade (Diagnóstico). $\mathrm{Na}$ realidade, pacientes que têm um mesmo diagnóstico desenvolvem diferentes evoluções e resultados, Revista Serviço Social \& Saúde. UNICAMP Campinas, v. VII-VIII, n. 7-8, Dez. 2009 
assim como pacientes que têm uma mesma terapia farmacológica desenvolvem diferentes evoluções e resultados. Por isso, o diagnóstico sozinho, assim como o fato de que o paciente tome alguns psicofarmácos, não orienta para um prognóstico. O diagnóstico pode ajudar a estabelecer a oportunidade de uma terapia farmacológica, porém não a estabelecer estratégias de intervenção mais complexas e articuladas [...] O que determina resultados tão diferentes é: boa ou má utilização das medidas terapêuticas; a existência e/ou influência das variáveis "sombra" (SARACENO, 1994, p. 22, grifos do autor)

Desse modo, a pessoa com transtorno mental é restituída em sua integralidade e o foco da atenção dos profissionais de saúde mental se amplia para além dos sintomas e dos medicamentos, para as dimensões sociais da vida. Assim, os determinantes sociais do processo saúde-doença ganham ênfase e o social passa a ser uma dimensão que ganha evidência na intervenção de todos os profissionais de saúde mental.

O modelo assistencial psiquiátrico brasileiro encontra-se em processo de transição, de um modelo segregador, excludente, para um modelo de serviços aberto, comunitário e preservador da cidadania. Muito embora persista a coexistia de lógicas/modelos, um dos principais avanços é no reconhecimento da pessoa com transtorno mental como sujeito de direitos.

Neste contexto, o próprio modelo hospitalocêntrico tem sido exigido a se modernizar. A institucionalização do Programa Nacional de Avaliação dos Serviços Hospitalares - PNASH - versão hospitais psiquiátricos (Portaria GM/MS 3.408, de 05 de agosto de 1998) materializa o investimento no sentido de "garantir a qualidade mínima necessária aos serviços de saúde”. 
No contexto mudancista novos processos de trabalho são requeridos exigindo novas técnicas e tecnologias e novas formas de trabalho em saúde e, particularmente em saúde mental, calcadas no trabalho em equipe multiprofissional e interdisciplinar, no território de vida da pessoa enferma, atuação em rede sócio-assistencial, intersetorial, calcada no controle social, na promoção da cidadania e da autonomia possível de usuários e familiares.

O novo perfil do trabalhador em saúde tem por traços: a ação polivalente; com competências múltiplas e que atue mais com o intelecto, com a intuição. Ou seja, a clássica divisão social do trabalho que segmenta trabalho intelectual do trabalho manual, planejamento e execução, se rompe.

Constrói-se um trabalhador coletivo sintetizado no termo Técnico de Referência - TR, que é o profissional que acolhe e assegura um vínculo com os usuários dos serviços e que tem "sob sua responsabilidade monitorar junto com o usuário o seu projeto terapêutico, (re) definindo, por exemplo, as atividades e a frequiência de participação no serviço. O TR também é responsável pelo contato com a família e pela avaliação periódica das metas traçadas no projeto terapêutico, dialogando com o usuário e com a equipe técnica do CAPS" (BRASIL, 2004a).

Consequentemente, não só o médico ganha destaque nas intervenções e na direção dos serviços. Outros profissionais passam a ter suas práticas valorizadas. Muitos Caps, inclusive alguns hospitais psiquiátricos e coordenações estaduais e municipais passam a ser comandados por profissionais não médicos.

Para cimentar os avanços acima, no campo da formação profissional em saúde, são implantadas as Diretrizes Curriculares Nacionais do Curso para os Cursos Universitários da Área da Saúde (ALMEIDA, 2003). As diretrizes têm um caráter interprofissional, que corrobora uma formação parametrada pelo reforço aos postulados 
do Sistema Único de Saúde, orientado para a promoção à saúde e determinantes sociais do processo saúde-doença.

Com todo este contexto e contorno, o movimento de reforma psiquiátrica impõe novas demandas para todos os profissionais da saúde mental, particularmente para os assistentes sociais, que não são profissionais da saúde, mas tem atualmente este campo numericamente como um de seus principais espaços sócio-ocupacional. A Resolução 287/98 do Conselho Nacional da Saúde reconhece o Serviço Social como uma das 14 profissões da área da saúde, mas no interior da categoria há um acúmulo ainda incipiente nesta arena.

\section{DEMANDAS POSTAS PARA O ASSISTENTE SOCIAL NA SAÚde MENTAL}

Historicamente, a inserção do assistente social em saúde mental no Brasil tem início em 1946, a partir do trabalho em instituições voltadas para a infância. Em seguida o assistente social é incorporado aos hospitais psiquiátricos, atuando na "porta de entrada e saída" dos serviços, como informa Vasconcelos (2007). As ações dos assistentes sociais no espaço hospitalar volta-se preponderantemente para levantamentos de dados sociais dos PTMs e seus familiares; confecção de atestados sociais; encaminhamentos para a rede sócio-assistencial e difusão de informação e orientação

social, sobretudo para regularizar a documentação e acessar benefícios sociais, aposentadorias.

Gradativamente, no interior dos próprios hospitais psiquiátricos os assistentes sociais passam a atuar em vários setores: plantão psiquiátrico, pavilhões - divididos por sexo (masculino e feminino) e faixa etária (pavilhão infantil ou geriátrico); hospitais-dia e ambulatórios). 
Entre os serviços típicos da reforma psiquiátrica, Caps, Caps infanto-juvenil, Caps-álcool e drogas, residências terapêuticas e atenção primária, observa-se os assistentes sociais assumindo uma multiplicidade de funções, sobretudo como gestores, coordenadores, planejadores, técnicos, supervisores, dentre outras.

$\mathrm{Na}$ área empresarial, sobretudo em empresas de economia mista, em hospitais gerais e algumas instituições públicas tem crescido o número de assistentes sociais coordenando programas de alcoolismo, tendo por público alvo os funcionários ou servidores públicos e seus familiares. A área da assistência social tem se alargado em direção à saúde mental, através de programas de abrigamento de idosos ex-moradores de hospitais psiquiátricos, população de rua com transtornos mentais, mas fora de crise e mais recentemente, tem criado coordenadorias de dependência química, voltada para os adolescentes em cumprimento de medidas sócio-educativas.

Além dessas atividades é comum encontrar assistentes sociais em atividades de docência, supervisão de serviços e de pesquisa na área da saúde mental, no Serviço Social Jurídico abordando questões de interdições, tutela, curatela, dentre outros.

Cada serviço traz necessidades particulares para a prática profissional, exigindo adequações a múltiplas temáticas e segmentos no interior da saúde mental e a heterogêneos processos de trabalho, a exemplo da coordenação de uma residência terapêutica.

Além disso, a história do serviço e da equipe multiprofissional bem como as habilidades de cada um de seus membros, a correlação de forças internas e externas às equipes também vão influir nas possibilidades da prática profissional do assistente social. 
Em suma, observa-se que são várias as demandas colocadas pela nova política, novo paradigma e novos serviços, com novos processos de trabalho para todos os profissionais da saúde mental e particularmente para os assistentes sociais. Mas,

As múltiplas competências e atribuições para as quais é chamado a exercer no mercado de trabalho exigem uma interferência prática nas variadas manifestações da questão social, tal como experimentadas pelos indivíduos sociais. Essa exigência, no âmbito da formação profissional, tendeu a ser unilateralmente restringida ora aos procedimentos operativos, ora à qualificação teórica como se dela automaticamente derivasse uma competência para a ação (IAMAMOTO, 2007, p. 240).

Os assistentes sociais durante seu curso de graduação não têm uma formação específica em saúde mental.

Os estágios curriculares e extra-curriculares em saúde ainda tem uma relação intensa com o modelo hospitalocêntrico, haja vista que muitos serviços se conformam como hospitais de ensino, sendo vinculados com as universidades, que ainda disseminam uma formação pautada fortemente no modelo biomédico, separando os sintomas do contexto social, no geral, preparando de maneira tímida para o trabalho em equipe multiprofissional e interdisciplinar. Isto é, não é fomentado durante o processo formativo o diálogo entre as diferentes ciências e profissões, o que é requerido no dia a dia assistencial.

No contexto reformista em saúde mental tende a haver uma crise de identidade entre os profissionais das diferentes categoriais profissionais, demandados a alargar seu 
horizonte interventivo para o social, até então vistos como dimensão inerente à prática do assistente social $^{4}$.

Vale lembrar que nem a questão social nem o social são exclusividades do assistente social. Uma vasta gama de objetos de intervenção dos assistentes sociais se situa na interface ${ }^{5}$ com outras profissões. Neste sentido, o trabalho em equipe pode constituir-se em uma arena de construção interdisciplinar ou de tensões, disputas corporativas e de saberes. Essas possibilidades podem estar reforçadas no próprio termo trabalhador coletivo construído no cerne dos novos serviços, com a figura do técnico de referência. Este "personagem” pode reforçar a diluição das fronteiras entre as diferentes categoriais profissionais, ampliando áreas de sombreamento, permitindo a interdisciplinaridade ou até acirrando o confronto entre as profissões.

De qualquer maneira, os novos serviços colocam o desafio de reconstrução das identidades e fazeres profissionais tradicionais.

O desafio é fazer convergir os olhares e práticas para a construção de algo novo “de modo a poder dar uma direção às diferentes intervenções que, guardando sua especificidade, não sejam conflitantes entre si, permitam alguma coerência no trabalho da equipe e tornem viável uma ação conjunta. Não é 'todo mundo fazendo a mesma coisa” nem 'cada um faz uma coisa diferente' (FIGUEIREDO; JARDIM, 2001, p. 66).

Como afirma Marilda Iamamoto

O trabalho coletivo não impõe a diluição de competências e atribuições profissionais. Ao contrário, exige maior clareza no

\footnotetext{
4 Interessantes observar que tem sido cada vez mais comum encontrar alunos que fazem concomitantemente o Curso de Serviço Social e Psicologia.... Que identidade predominará? Que identidade pode se construir na confluência entre o clinico e o social? Vale lembrar que há vários entendimentos no interior da própria psicologia, algumas se aproximando inclusive da questão social, tal como a psicologia comunitária.

${ }^{5}$ Interface definido como espaço de diálogo entre várias profissões. Áreas de sombreamento. Espaço de intervenção, de atribuições comuns entre várias profissões/profissionais (Cristóvam Belfort, em aula de Deontologia, em janeiro de 2008) Que quase sempre são profissões correlatas, mas nem sempre.
}

Revista Serviço Social \& Saúde. UNICAMP Campinas, v. VII-VIII, n. 7-8, Dez. 2009 
trato das mesmas e o cultivo da identidade profissional, como condição de potenciar o trabalho conjunto. $\mathrm{O}$ assistente social mesmo realizando atividades partilhadas com outros profissionais dispõe de ângulos particulares de observação na interpretação dos mesmos processos sociais e uma competência também distinta para o encaminhamento das ações (IAMAMOTO, 2002).

Dessa maneira, muito embora o assistente social não seja um profissional do campo psi nem da saúde, tem um olhar e uma contribuição singular para a área da saúde mental, historicamente legitimados, reconhecidos pela própria inclusão desta categoria na equipe multiprofissional.

Mas, nos novos cenários a identidade do assistente social em saúde mental encontra-se em processo de construção. A mesma é determinada por vários elementos: 1) pelo conjunto de fatores macroestruturais, que determinaram a emergência da profissão na sociedade brasileira. No caso da saúde mental é preciso resgatar historicamente os condicionantes da emergência do serviço social neste campo, o que foi realizado por Vasconcelos (2007); 2) pelos documentos legais que delimita as competências e atribuições dos assistentes sociais, destacando-se a Lei de Regulamentação da Profissão $n^{\circ}$ 8.662, de 07 de junho de 1993; o Código de Ética Profissional, Resolução CFESS n 290; a Resolução CFESS nº 383/99 de 29 de março de 1999 que caracteriza o assistente social como profissional da saúde; Resolução CFESS n 493/2006, de 21 de agosto de 2006, que dispõe sobre as condições éticas e técnicas do exercício profissional do assistente social; 3) pela visão de mundo e singularidade de cada profissional, pois, cada agente reproduz em sua prática profissional suas crenças e valores

Ramos (2003) ao analisar a identidade do assistente social nos Centros de Atenção Psicossocial no Ceará a partir da própria categoria e com os demais membros, Revista Serviço Social \& Saúde. UNICAMP Campinas, v. VII-VIII, n. 7-8, Dez. 2009 
de outras categorias profissionais da equipe, mostra que os assistentes sociais se auto qualificam como:

- Agente assistencial. Esta identidade está relacionada às funções tradicionais historicamente vinculadas ao Serviço Social, relacionadas às condições socioeconômicas dos usuários e às suas necessidades em acessar determinados recursos que viabilizem o acesso a direitos. Entre as demandas colocadas neste campo encontram-se o acesso aos benefícios sociais, sobretudo, benefício de prestação continuada, vale-transporte, aposentadorias, licenças dentre outros.

- Potencializador de mediações. O assistente social potencializa mediações em vários sentidos, articulando as relações do Caps com a rede sócioassistencial do município ou do Estado; a relação usuários-familiares e equipe de Caps; a relação do Caps com a comunidade/território; a relação entre os próprios profissionais do Caps. Neste sentido, o assistente social é um articulador por excelência, porque na prática cotidiana assume a condição de veiculador de informações entre os diferentes atores sociais que atuam a partir dos serviços de saúde mental.

- Agente complementar, colaborador. Historicamente o agente privilegiado em saúde é o médico. O assistente social já figurou como paramedico e agente complementar, subsidiário à ação das categorias que dominam o setor. Figura como um coadjuvante do processo de saúde mental, mas nem por isso com um estatuto ou importância menor.

- Agente político, da cidadania, dos direitos. Tal identidade auto referida pelos assistentes sociais está relacionada à gama de informações sobre 
legislação social que este profissional detêm e aciona para viabilizar o exercício de direitos por parte dos usuários dos serviços. O assistente social possui um amplo e difuso campo de intervenção circunscrito ao trato com a legislação social, a rede institucional, os mecanismos de acesso e restrição dos segmentos sociais aos institutos de regulação social, e, ainda, às ações de caráter imaterial voltadas para a mobilização de valores e comportamentos no universo das relações sociais (BARBOSA; CARDOSO; ALMEIDA, 1998, p.110).

Desse modo, o assistente social contribui no processo de acesso a determinados direitos pela veiculação de informação, aproximação dos canais garantidores de direitos e no fomento à criação de conselhos locais de saúde. De outra maneira, também, pode atuar como agente político no interior da própria equipe de saúde mental, pois é identificado como um profissional que faz circular as informações entre os diferentes membros da equipe; questiona o cotidiano institucional fazendo com que a equipe funcione e acione seu potencial em prol das necessidades dos usuários e do serviço.

- Agente terapêutico/terapeuta. Há um grupo significativo de assistentes sociais com formação específica em psicanálise, terapia de família ou fundamentados na teoria sistêmica, que se incluem no denominado Serviço Social Clinico. Há um intenso debate pela Internet e materializado em publicações do CRESS do Rio de Janeiro em torno desta identidade assumida por uma parcela de assistentes sociais. No debate sintetizado no livro Atribuições Privativas do Assistente Social e o "Serviço Social Clínico" Marilda Iamamoto entende que investir neste sentido é retornar a um passado profissional antes do Movimento de Reconceituação. Representantes da UERJ e do CRESS entendem que "os defensores do Serviço Social Clínico não estabelecem relação do seu modo de operar com o Código de Ética Profissional, com a Lei de Regulamentação da 
Profissão e com as Diretrizes Curriculares" (CRESSRJ, 2004, p. 17). Sintetizando, não é atribuição dos assistentes sociais ações no plano clínicoterapêutico. Apesar disto, por exemplo, há um número significativo de assistentes sociais com formação em terapia de família, que balizam suas práticas com estes fundamentos e não com base no Projeto Ético Profissional, como pode ser visualizado em Dócolas (2009).

Além dos profissionais com uma formação específica nos campos acima há um grupo de assistentes sociais que atuam nos serviços de saúde mental empregando na sua atuação com usuários e familiares técnicas de relaxamento, fundamentados na meditação ou Yoga.

Desse modo, uma pluralidade de entendimentos e ações começam a se desenhar entre os assistentes sociais da saúde mental. Talvez estes direcionamentos de alguns assistentes sociais na saúde mental se deva a uma necessidade do profissional de "mostrar serviço", dar uma materialidade para sua intervenção junto aos usuários e demais membros da equipe.

Especulativamente, pode estar subjacente a tais práticas a necessidade de ter alguma identidade com o campo clínico, mais valorizado na área da saúde mental, onde os profissionais do campo psi são os mais destacados.

Um outro elemento que pode ter contribuído na assunção destas práticas entre os assistentes sociais pode estar relacionado à ação dos novos serviços estar centrada nas necessidades dos usuários, ser uma ação conceituada como usuariocentrada, onde as atribuições e competências específicas da categoria tenderem a ser secundarizadas, fazendo emergir outras habilidades ou competências pessoais de alguns colegas. Desse modo, observam-se alguns assistentes sociais, por exemplo, coordenando oficinas de 
coral, por ter na música um hobby ou uma habilidade para além das suas atribuições profissionais.

De qualquer maneira, soa estranho em um contexto de valorização e difusão do social entre todas as categorias profissionais que integram o campo da saúde mental, alguns assistentes sociais buscarem exatamente no campo clínico o centramento de sua perspectiva teórica e interventiva.

Todavia, o assistente social em saúde mental não se auto-constrói. Sua identidade é construída nas relações sociais e a partir das demandas originárias do corpo de dirigentes das instituições, dos usuários dos serviços e na relação com os demais profissionais da equipe, que demandam ações do assistente social tendo em vista o que entendem ser as competências e atribuições deste profissional. Evidentemente, o próprio entendimento do profissional do Serviço Social e sua leitura acerca da legislação profissional também influirão nesta construção. Ramos (2003) ao avaliar a identidade do assistente social desenhada pelos demais profissionais da equipe informa que os mesmos apontaram o assistente social numa multiplicidade de dimensões, numericamente mais significativas do que aquelas traçadas pelos próprios assistentes sociais, como:

- Agente assistencial;

- Potencializador de mediações;

- Profissional auxiliar, complementar

- Agente terapêutico/ terapeuta

- Agente político/da cidadania, dos direitos

- Profissional da família.

O assistente social comumente é identificado pelos demais membros da equipe de saúde mental como o profissional que tem mais habilidade e competência 
para atuar diretamente com os grupos familiares, sobretudo de baixa renda ${ }^{6}$. Neste sentido é demandado a realizar: orientação social; analisar a dinâmica familiar; fazer atendimento ao grupo e realizar visita domiciliar.

Trabalhamos com famílias atuando no processo de viabilização dos direitos e dos meios de exercê-los. Requer considerar as relações sociais e a dimensão de classe que as conformam, sua caracterização sócio-econômica, as necessidades sociais e os direitos de cidadania dos sujeitos envolvidos, as expressões da questão social que se condensam nos grupos familiares, as políticas públicas e o aparato de prestação de serviços sociais que as materializam (CRESSRJ, 2004, p. 39).

Para tanto, o assistente social articula o trabalho com os grupos familiares com a intersetorialidade, pois, tem que atuar em conjunto com as demais políticas públicas, sendo, em tese, um exímio conhecedor da rede sócio assistencial e de seus recursos. Vale lembrar que todos os profissionais da equipe de saúde mental atuam de maneira direta mesmo que, no geral, pontual com as unidades familiares. Todavia, é o assistente social que temporalmente tende a ter maior dedicação a este grupo no seu cotidiano interventivo. Há ainda uma tendência das políticas públicas se matriciarem no grupo familiar. Historicamente, o assistente social tem uma relação de intervenção construída com as famílias, mas a categoria não construiu um arcabouço teórico metodológico próprio para atuar com este grupo, o qual necessita de maiores investimentos do Serviço Social.

- Agente educativo, socializador. O assistente social ao conferir novos tons à realidade da pessoa com transtorno mental, ao viabilizar os direitos de cidadania, é requisitado a ser um agente educativo, socializador. É da natureza do conteúdo de seu trabalho a dimensão pedagógica, o trabalho sócio-educativo, de educação em saúde até

\footnotetext{
${ }^{6}$ Tal fato deve-se à identificação histórica da profissão com a pobreza e a questão social. Revista Serviço Social \& Saúde. UNICAMP Campinas, v. VII-VIII, n. 7-8, Dez. 2009
} 
mesmo com a equipe de saúde mental, pois, é o profissional que em função de seu ofício faz a informação circular entre todos os atores sociais e institucionais.

- Profissional da inserção. O assistente social tem sido percebido como profissional da inserção exatamente pela articulação que promove entre as diferentes políticas públicas, para mobilizar recursos com o objetivo de reintegração social da pessoa com transtorno mental. Neste sentido, alguns assistentes sociais têm inclusive se engajado em programas de geração de renda e cooperativas de trabalho para inserir a PTM em atividades laborativas significativas.

- Profissional do controle. Historicamente o assistente social também teve um papel disciplinador dos usuários dos serviços, ao ser o profissional encarregado de veicular normas e rotinas institucionais, em algumas circunstâncias até mesmo assumindo o papel de fiscalizador de seu cumprimento.

- Agente multiplicador. O assistente social na sua condição de veiculador de informação acaba por se constituir como um agente multiplicador da mesma, ao difundir informações através dos veículos de massa, como rádios comunitárias; palestras em serviços comunitários ou pelos demais serviços da rede sócio-assistencial.

Assim, uma multiplicidade de atribuições e competências cerca a identidade e o perfil profissional dos assistentes sociais em saúde mental, que precisam receber um tratamento mais aprofundado. A seguir, a abordagem com as unidades familiares será destacada, pela importância que estes grupos adquiriram em um contexto de cuidado comunitário. 


\section{A FAMÍlIA NO MOVIMENTO DA REFORMA PSIQUIÁTRICA BRASILEIRA}

As unidades familiares ganham visibilidade, inicialmente, no interior do movimento da Reforma Psiquiátrica Brasileira ao se constituir como um ator político, se organizando para defender os direitos das pessoas com transtorno mental.

Nos anos 90 é que crescem o número de pesquisas brasileiras orientadas para a relação dos grupos familiares com a pessoa com transtorno mental. Surge uma multiplicidade de análises, que apontam na seguinte direção, como explicita Rosa (2002):

1) Como um recurso como outro qualquer, no rol das estratégias de intervenção (SANT’ANNA; FONTOURA, 1996)

2) Como um lugar de possível convivência da pessoa com transtorno mental, desde que os laços relacionais possam ser mantidos ou reconstruídos.

3) Como sofredora, pois, é influenciada pela convivência com uma pessoa com transtorno mental e, desse modo, precisa ser "tratada", assistida, recebendo suporte social e assistencial (MOTTA, 1997);

4) Como um sujeito da ação. Sujeito coletivo, ator político que se organiza em associações específicas, na opinião de Sant'Anna e Fontoura (1996) e, ainda, sujeito avaliador dos serviços, conforme Pereira (1997) e construtora da cidadania da pessoa com transtorno mental;

5) Como provedora de cuidados, desde que os serviços de saúde mental visam atuar sobre os momentos de crise, tratando e não prestando cuidados contínuos. E também porque a família é o principal agente potencializador de mediações entre a pessoa com transtorno mental e a sociedade, constituindo historicamente um lugar privilegiado de cuidados e reprodução social. 
Essas perspectivas não são excludentes entre si. Ao contrário, se entrelaçam, indicando simultaneamente a variedade de necessidades que emergem no interior dos grupos familiares; a pluralidade de identidades desta instituição e exigências de flexibilidade dos serviços e das práticas profissionais para contemplar a heterogeneidade nesta arena.

Historicamente, o modelo hospitalocêntrico desenvolveu uma pedagogia de exclusão do grupo familiar, ao restringi-la a mera informante do histórico da enfermidade da pessoa com transtorno mental; a ser um recurso ocasional ou "visita" pontual, sendo invisibilizada na sua condição de provedora de cuidados contínuos, no plano doméstico.

Neste modelo de gestão as abordagens dirigidas às famílias eram pontuais e limitadas a algumas reuniões familiares (no geral palestras) e atendimentos individuais do grupo. A maioria dos profissionais da equipe fazia algum tipo de atendimento com as famílias, mesmo que de maneira assistemática e descontínua. Havia implicitamente uma divisão de trabalho na abordagem do grupo familiar, como identifica Rosa (2003). O médico, sobretudo no ato da admissão, para colher informações sobre o histórico das enfermidades, dos sintomas. Os enfermeiros, no geral, por ocasião da alta hospitalar, para realizar orientações sobre o prosseguimento do tratamento, via ambulatorial e cuidados com as medicações. Os assistentes sociais, durante o processo de internação, coordenando reuniões de famílias, no geral comandado por ações sócio-educativas, abordando uma variedade de questões, tais como normas e rotinas institucionais; mudanças no modelo assistencial; direitos; manejo da pessoa com transtorno mental no ambiente doméstico e difusão de conhecimentos sobre os diferentes quadros diagnósticos e medicamentos, permitindo troca de experiência entre os diferentes cuidadores familiares. 
Mudanças legislativas sinalizam no sentido de uma outra incorporação das famílias nos projetos terapêuticos dos serviços de saúde mental.

A portaria $n^{\circ}$. 251/GM de 31 de janeiro de 2002, que estabelece diretrizes e normas para a assistência hospitalar em psiquiatria e reclassifica os hospitais psiquiátricos prevê, no desenvolvimento dos projetos terapêuticos, o preparo para o retorno à residência/inserção domiciliar e uma abordagem dirigida à família no sentido de garantir orientação sobre o diagnóstico, o programa de tratamento, a alta hospitalar e a continuidade do tratamento.

As famílias, sobretudo na fase inicial da eclosão do transtorno mental, têm um papel fundamental na construção de uma nova trajetória para o seu ente enfermo, desde que seus recursos emocionais, temporal e econômico sejam bem direcionados pelos trabalhadores e serviços de saúde mental.

É importante destacar que nenhum grupo familiar está preparado para ter um membro com transtorno mental em seu meio (MELMAN, 2001). Não está capacitado para prover cuidado de uma pessoa adulta que tem um transtorno mental, cujo cuidado doméstico é complexo, envolvendo intensas responsabilidades e dedicação temporal.

A complexidade se manifesta em uma variedade de acontecimentos. Em primeiro lugar, ninguém espera ter uma pessoa com transtorno mental no meio familiar. Trata-se de um evento imprevisto na trajetória da vida familiar. Em segundo lugar, no imaginário da sociedade moderna, é previsto que uma pessoa adulta seja emancipada, tenha incorporado o auto cuidado e seja independente, não necessitando de cuidados de terceiros. Em terceiro lugar, tratar de uma pessoa adulta, com transtorno mental, no ambiente doméstico é uma tarefa complexa, que exige preparo mínimo do cuidador, para lidar com uma gama imensa de ocorrências. Não é suficiente ter amor. Em quarto lugar, os grupos familiares são demandados a se reposicionar em relação a uma série de 
questões envolvendo inclusive sentimentos. Em quinto lugar, os grupos familiares encontram-se sobrecarregados com uma série de demandas oriundas de uma conjuntura de restrição de gastos sociais e pelas repercussões das mudanças, sobretudo, demográficas em seu interior.

Quando emerge uma pessoa com transtorno mental as famílias são demandadas primeiramente a enfrentar a nova situação, tendo que ao mesmo tempo compreender a própria enfermidade, a dinâmica dos serviços de saúde mental e manejar seus próprios sentimentos e recursos.

Frequentemente o familiar cuidador se isola no plano doméstico para cuidar, porque não tem preparo mínimo para cuidar e não consegue manejar a pressão social e o estigma que também o atinge.

Enquanto não são treinados para o conhecimento da enfermidade, passa por processos de confronto com a pessoa com transtorno mental. Por exemplo, lidam com o delírio como sendo "besteiras", "bobagens". Alguns chegam a querer corrigir a maneira da pessoa com o transtorno mental ver o mundo (via delírios), confrontando-se com o mesmo. No caso de uma depressão é comum os familiares afirmarem que "Sugeri pra ela procurar um curso, passear, mas ela não vai. Ela não se ajuda”. É difícil para o familiar, sem treinamento, entender que a depressão atinge o centro volitivo da pessoa, não sendo expressão da "preguiça" ou má vontade.

$\mathrm{O}$ retrato dessas trajetórias facilita a avaliação do grupo familiar e mostra a importância de inclusão das famílias nos projetos terapêuticos e pedagógicos dos serviços de saúde e assistência.

Nos projetos terapêuticos dos Caps os familiares são incorporados como "parceiros no tratamento" (BRASIL, 2004c) sendo estimulados a participar do cotidiano dos serviços. "Os familiares podem participar dos" Caps, não somente incentivando o 
usuário a se envolver no projeto terapêutico, mas também participando diretamente das atividades do serviço, tanto internas como nos projetos de trabalho e ações comunitárias de integração social (IDEM, p. 29).

Observa-se em alguns Caps e outros serviços de saúde mental o engajamento dos familiares em redes de solidariedade, através de grupos de mutua ajuda e troca de suporte, mas ainda de maneira tímida. É difícil mobilizar os familiares para ações grupais porque: 1) a cultura e pedagogia dos serviços, historicamente, as excluiu; 2) participar para alguns familiares é um trabalho a mais, uma sobrecarga, exigência a mais; 3) alguns serviços se limitam a oferecer um espaço para a família restrito a palestra, que muitas vezes, é desfocada de suas necessidades; 4) os horários dos encontros nem sempre é compatível com os horários disponíveis dos familiares.

Mas, com mudanças que levem em conta o acima explicitado e com o estímulo e a consolidação de engajamento dos familiares na abordagem pedagógica e terapêutica dos serviços de saúde mental, espera-se construir uma nova etapa na trajetória dos mesmos, através de ações mais solidárias e partilhadas.

Destaca-se que as unidades familiares encontram-se muito sobrecarregadas na atual conjuntura, com o crescente empobrecimento e mudanças demográficas. Os serviços de saúde mental têm que contribuir inclusive neste sentido, sobretudo aliviando o peso gerado pelas demandas de cuidado, dividindo encargos com as familias.

\section{ATUAÇÃO DO ASSISTENTE SOCIAL COM O GRUPO FAMILIAR}

O assistente social, frequentemente, contribui com os cuidadores familiares através do trabalho sócio-educativo, promovendo a troca de informações e vivências, para que, sobretudo os cuidadores familiares saiam de seu isolamento pessoal e social, tendo sua carga de trabalho aliviada, apoiada. Quando passam a trocar informações com 
outros cuidadores familiares é comum perceberem que muitas vivências são semelhantes e que não foram os "únicos escolhidos para sofrer neste mundo". Inclusive há uma pressão social para que as famílias não publicize, não remeta para a arena das políticas públicas a sua situação. Neste sentido é paradigmático o depoimento de um familiar com um artigo no livro Minas sem manicômios (2004) "algumas pessoas acharam que estávamos expondo demais nossos dramas familiares" (ORNELAS, 2004, p. 83).

A troca de vivência potencializa novas estratégias de cuidado, tendo em vista que não há uma "receita pronta" para cuidar, muito embora alguns familiares cheguem às reuniões com a expectativa do acontecimento de uma mágica, que mude substancialmente suas vidas.

É importante desconstruir esta expectativa, pois, muitos familiares consideram que "só quem estudou (isto é, esteve em uma universidade) sabe cuidar bem dele"

Todavia, os familiares cuidadores historicamente aprenderam a cuidar no "ensaio e erro" (ROSA, 2003) das exigências cotidianas, no geral, sem as salvaguardas/respaldo dos profissionais de saúde mental. É importante reconstruir as trajetórias dos familiares na construção de respostas para os desafios cotidianos, para reforçar o que foi aprendido e potencializando os próprios recursos internos do grupo. Potencializando um conhecimento que os cuidadores familiares construíram e nem sempre se apercebem disso.

Com a criação de espaços próprios no interior do serviço (ou no território) para reunir os grupos familiares e permitir a interação, com acompanhamento de um ou mais profissionais (mais comumente o assistente social atua em conjunto com as psicólogas ou enfermeiras), pode-se observar mudanças significativas na qualidade de vida destes cuidadores. 
Interessante que muitas reuniões denominadas de familiares, no geral, se reduzem a reuniões de mulheres, comumente, mães, esposas, filhas e irmãs. É importante chamar outros membros do grupo familiar para esta arena, resgatar, por exemplo, o homem como cuidador, colocando assim em evidência as questões de gênero no interior das famílias.

Os assistentes sociais com toda sua bagagem sobre investigação/análise social, podem contribuir realizando levantamentos sobre o perfil das famílias usuárias dos serviços de saúde mental, para:

- Conhecer que tipo de arranjo doméstico prevalece e a heterogeneidade de arranjos existentes e como repercutem no provimento de cuidado;

- Como as mudanças demográficas repercutiram sobre a organização do grupo, tendo por foco o provimento de cuidado;

- Analisar a dinâmica familiar. Como se dão as relações sociais. Quem provê renda? Quem provê cuidados? Quem é a autoridade no grupo? Qual o lugar que a pessoa com transtorno mental ocupa no grupo? Qual a qualidade das relações familiares? Predominam os sentimentos positivos ou negativos entre seus membros? Como por exemplo, um PTM que recebe um benefício em comparação a um outro que não o têm, são tratados por suas famílias? Como este "ganho secundário" repercute no grupo?

- Identificar a posição da pessoa com transtorno mental no grupo; os valores/a ética que preside o provimento de cuidado de: "dar, receber, retribuir" (SARTI, 1996); qual o clima que prevalece em relação à PTM: hostilidade ou solidariedade;

- Conhecer como a família vive, como mora. Qual o status do grupo no seu meio. Identificar os recursos que lança mão na rede de parentesco, de vizinhança e Revista Serviço Social \& Saúde. UNICAMP Campinas, v. VII-VIII, n. 7-8, Dez. 2009 
rede sócio-assistencial. Identificar os fatores de proteção e de risco existentes no meio familiar. Levantar os fatores sociais de vulnerabilidade do grupo.

- Conhecer os recursos da rede sócio-assistencial à disposição dos cuidadores familiares;

- Levantar os significados, o imaginário e as práticas sociais sobre o louco e a loucura em seu território existencial.

Com a sistematização destas informações, o assistente social pode devolvê-las aos grupos familiares, propiciando o debate e a troca de informações entre os provedores de cuidado.

É importante o investimento dos profissionais para que outros membros das famílias passem a participar da gestão do cuidado cotidiano da pessoa com transtorno mental, que tende a ficar ao encargo de uma única pessoa.

\section{CONSIDERAÇÕES FINAIS}

O movimento da reforma psiquiátrica possibilitou múltiplas inserções dos assistentes sociais em saúde mental, ainda pouco explorada na literatura da categoria.

Pela implicação histórica do assistente social com a abordagem das famílias de baixa renda observa-se parco investimento na construção de abordagens significativas, que potencializem conhecimentos e intervenções que possam dar maior visibilidade à categoria no campo da saúde mental.

Os assistentes sociais tem que investir mais na sistematização de suas experiências em saúde mental e, sobretudo com o grupo familiar, aprofundando os diferentes ângulos implicados na matéria. 


\begin{abstract}
The objective of this text is to initiate an analysis of the different insertions of social workers in mental health from the implementation of the Brazilian Psychiatric Reform Movement, and by highlighting the work with family groups. It is based on the rescue of professional literature and teaching experience from the reality Northeast. In the context of reforming the social actions are in process of construction, requiring greater systematization and depth.
\end{abstract}

KEYWORDS: Social Worker, Mental Health, Professional Practice.

\title{
REFERÊNCIAS BIBLIOGRÁFICAS
}

ALMEIDA, M. (Org.) Diretrizes curriculares nacionais para os cursos universitários da área da saúde. Londrina: Rede Unida, 2003.

AMARANTE, P. Loucos pela vida: a trajetória da reforma psiquiátrica no Brasil. Rio de Janeiro: SDE/ FIOCRUZ, 1994.

O homem e a serpente: outras histórias para a loucura e a psiquiatria. Rio de Janeiro: FIOCRUZ, 1996.

BARBOSA, R. N. C.; CARDOSO, F. G.; ALMEIDA, N. L.T. A categoria "processo de trabalho" e o trabalho do assistente social. Revista Serviço Social \& Sociedade, ${ }^{\circ}$ 58, p.109-130, 1998.

BRASIL, Legislação em Saúde Mental - 1990-2004. 5ª Ed. Brasília: Ministério da Saúde, 2004a.

. Clínica Ampliada. Brasília: Ministério da Saúde, 2004b.

. Saúde Mental no SUS: Os centros de atenção psicossocial. Brasília: Ministério da Saúde, 2004c.

. Saúde Mental no SUS: acesso ao tratamento e mudança do modelo de atenção. Relatório de Gestão 2003-2006. Ministério da Saúde: Brasília, 2007. 
Relatório de gestão 2003-2006: Saúde Mental no SUS: acesso ao tratamento e mudança no modelo de atenção. Brasília: Ministério da Saúde, 2007.

CRESSRJ. Atribuições privativas do assistente social e o "Serviço Social Clínico". Rio de Janeiro: CRESS. 2004.

DELGADO, P. G. As razões da tutela: Psiquiatria, justiça e cidadania do louco no Brasil. Rio de Janeiro: TeCorá, 1992.

DÓCOLAS, G. M. O Serviço Social em um CAPS. In: Crianças e adolescentes vulneráveis: o atendimento interdisciplinar nos Centros de Atenção Psicossocial. Porto Alegre: Artmed, 2009, p. 215-36.

FIGUEREDO, A.C.; JARDIM, S. R. Formação de recursos humanos, trabalho e saúde mental. In: FIGUEIREDO, A.M; CAVALCANTI, M.T. (Org) A reforma psiquiátrica e os desafios da desinstitucionalização. Rio de Janeiro: Edições IPUB, 2001, p. 59-68. IAMAMOTO, M. V. Projeto profissional: espaços ocupacionais e trabalho do assistente social na atualidade. In: Atribuições privativas do(a) assistente social em questão, Brasília: CFESS, 2002.

Serviço Social em tempo de capital fetiche: capital financeiro, trabalho e questão social. São Paulo: Cortez, 2007.

MELMAN, J. Família e doença mental: repensando a relação entre profissionais de saúde e familiares. São Paulo: Escrituras, 2001.

MOTTA, A. A. A ponte de madeira: a possibilidade estruturante da atividade profissional na clinica da psicose. São Paulo: Casa do Psicólogo, 1997.

ONU. Organização das Nações Unidas. A proteção de pessoas com problemas mentais e a melhoria da assistência em saúde mental. [S.1.: s.n.]. Mimeografado. ORNELAS, C. (2004). Da família ao espaço público, em defesa da vida. Em: Minas sem manicômios. Belo Horizonte: Fórum Mineiro de Saúde Mental, 2004, p. 79-87. 
ORGANIZAÇÃO PANAMERICANA DE SAÚDE. Reestruturação da assistência psiquiátrica: bases conceituais e caminhos para sua implementação. Milão: OPS, 1990. PEREIRA, R. C. Lugar de louco é no hospício? Um estudo sobre representações sociais em torno da loucura no contexto da reforma psiquiátrica. Rio de Janeiro: FIOCRUZ/ ENSP, 1997. Dissertação de Mestrado em Saúde Pública.

RAMOS, R.A. As representações sociais sobre a prática profissional do assistente social nos centros de atenção psicossocial no Ceará. UFPE/Programa de Pós Graduação em Serviço Social. Mestrado. Recife, 2003.

ROSA, L.C. S. Os saberes construídos sobre a família na área da saúde mental. Revista Serviço Social \& Sociedade, $n^{\circ} 71$, p. 138-64, 2002.

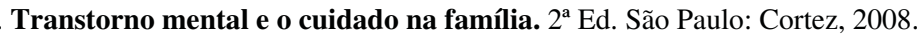

ROTELLI, F. Desinstitucionalização. São Paulo: Hucitec, 1990.

SANT'ANNA, D., FONTOURA, E.C.A. Desinstitucionalização; com a palavra a família. Rio de Janeiro: UFRJ/IP, 1996. Monografia. Especialização em Terapia Familiar.

SARACENO, B. Manual de Saúde Mental. São Paulo: Hucitec,1994.

Libertando identidades: da reabilitação psicossocial à cidadania possível. Rio de Janeiro: Instituto Franco Basaglia/Te Cora, 1999.

SARTI, C. A. A família como espelho - um estudo sobre a moral dos pobres. Campinas: Editora Autores Associados, 1996.

VASCONCELOS, E. M. Saúde Mental e Serviço Social: o desafio da subjetividade e da interdisciplinaridade. São Paulo: Cortez, 2007. 
